\title{
Elementos da fiscalidade de Minas Gerais provincial
}

Fiscal Aspects in Brazilian Province

Minas Gerais

\author{
Cristiano Corte Restitutti \\ Doutorando em História pela \\ Universidade de São Paulo (FFLCH/ \\ USP - São Paulo/Brasil) \\ e-mail: ccr@usp.br
}

\begin{abstract}
Resumo
Este artigo trata das transformações da fiscalidade colonial de Minas Gerais na formação do Estado do Brasil. Os sistemas fiscais das provincias foram construídos em ritmos diferenciados. 0 caso de Minas Gerais apresenta condições especificas, devido à estrutura elaborada e severa da fiscalidade colonial. Destarte, trata-se da inserção de Minas na territorialidade do Império, abrindo seus caminhos secularmente fechados pela política metropolitana. Analisamos o caso de Minas Gerais a partir da evolução de dois tributos: os dizimos e os direitos de entrada. Estes impostos coloniais foram arrecadados em Minas Gerais com poucas modificações até c.1840. Os dízimos transmutaram-se em taxas de exportação em quase todo o Brasil durante a década de 1820, mas em Minas Gerais a transição foi tardia. Os direitos de entrada foram considerados privativos da esfera fiscal imperial, porém foram reeditados em Minas Gerais Provincial através de modalidades de taxas de barreira. A consolidação destes títulos de receita no sistema fiscal de Minas Gerais conflitou com a esfera fiscal geral e com as de outras provincias.
\end{abstract}

\begin{abstract}
This article deals with the transformations of the colonial fiscality of Minas Gerais in the formation of the Brazilian State. The fiscal systems of the provinces were built up in different rhythms. The case of Minas Gerais has specific conditions due to the complex and severe structure of the colonial fiscality. In this way, it is about the emerging of Minas in the territoriality of the Empire, opening its ways that have been secularly closed by the metropolitan policy. We analyse the case of Minas Gerais focusing the evolution of two of the main tributes of the Captaincy: the dizimos (tax on production) and the direitos de entrada (tax on imports). These taxes were collected in Minas Gerais with few modifications until the 1840s. The dizimos evolved to tax on exports in most provinces during the 1820s, but, in Minas Gerais, it was a late transition. The direitos de entrada were considered privative of the Imperial fiscal system, however it was recriated in Minas Gerais through modalities of toll fees. The consolidation of the forms of income in Minas Gerais conflicted with the Imperial fiscal system and with other provinces.
\end{abstract}

\section{Palavras-chave}

sistema fiscal, Minas Gerais, Império do Brasil

\section{Keywords}

tax system, Minas Gerais, Brazilian Empire 
IGLÉSIAS, Francisco. Politica Econômica do Governo Provincial Mineiro (1835-89). Rio de Janeiro: Ministério da Educação e Cultura Instituto Nacional do Livro, 1958. p.173.

Ibidem, p.173-195.
Ibidem, p.176. Iglesias identifica a gênese do aparato fiscal provincial na lei geral de 31 de outubro de 1835, artigo 9, parágrafo 6, que "enumera os títulos da receita geral e explicita que, às Provincias, 'cabem os restantes'." (Ibidem, p.173-188). Esclarece Tessitore que "esse parágrafo apenas definiu com maior precisão a partilha dos dizimos", cabendo à esfera geral a fiscalização dos gêneros exportados para o exterior e "o restante pertenceria à renda provincial" (TESSITORE, Viviane. As Fontes $d a$ Riqueza Pública. 1995. Dissertação de Mestrado. Faculdade de Filosofia, Letras e Ciências Humanas, Universidade de São Paulo, São Paulo, 1995. p.150).

A lei orçamentária geral de 24 de outubro de 1832 para servir em 1833/34 forneceu as diretrizes para a definição da a receita provincial mineira para o mesmo exercicio, cuja consolidação foi apresentada na lei mineira $n^{\circ} 12$ de 1835

Sobre estes titulos da fiscalidade mineira na Colônia e no Primeiro Reinado, vide, dentre outros: MATOS, Raimundo José da Cunha. Corografia Histórica da Província de Minas Gerais. Vol. 2. Belo Horizonte: Itatiaia; São Paulo: Edusp, 1981. p.223-250.

As principais fazendas secas verificadas nos registros eram tecidos, ferragens, armas, louças, quinquilharias, etc., ou seja, mormente artefatos estrangeiros. As fazendas molhadas importadas era majoritariamente sal, além de vinho, aguardente do reino e da terra, vinagre, bacalhau, trigo, azeite, espíritos diversos, etc. (ESCHWEGE, Guilherme, Barão de. Notícias e Reflexões Estatísticas da Província de Minas Gerais. Revista do Arquivo Público Mineiro, n.4, p. 737-62, 1899, p.750-751).
A história financeira apresenta enormes dificuldades. A complexidade natural do problema é agravada por suas condições no tempo: falta de uma diretriz segura e de método, terminologia imprecisa ou indiscriminação de títulos, nenhum rigor nas informações ${ }^{1}$

Em sua clássica tese de livre-docência, Francisco Iglesias felicitava-se por não ter como objeto a história financeira da província de Minas Gerais. Mas, ao definir a "política econômica" da província como objeto de estudo, o historiador mineiro não pôde ignorar a matéria. As dificuldades citadas pelo autor - as leis não seguem diretriz de método, nem de terminologia, nem de discriminação de títulos - proporcionaram negociação entre os agentes fiscais e contribuintes e geraram conflitos com as esferas da receita geral e de outras províncias. ${ }^{2}$

A fiscalidade como instrumento de politica econômica provincial nasceu na Regência do Império do Brasil. Mas a fiscalidade como fardo aos atos tributáveis foi elemento crucial da economia da Capitania de Minas Gerais e o sistema fiscal da Província foi uma continuação do sistema anterior. Alguns "novos" itens da receita regular provincial eram notórios aos mineiros há muitas décadas ou mesmo desde o século XVIII.

Independente o Brasil em 1822, a província herdou o aparato fiscal da capitania. 0 fisco provincial foi montado apenas na década de 1830, quando no período regencial houve esforços para definição da esfera da receita geral. As primeiras leis orçamentárias da Regência enumeraram os títulos da receita geral, deixando implícito que às províncias cabiam os restantes. Segundo Iglesias, a fiscalidade provincial nasceu após a instalação da Assembléia Provincial em 1835 e o exercício financeiro de 1835/36 é por ele considerado o primeiro da província de Minas Gerais3. Porém, este foi de fato o terceiro exercício. A Junta da Fazenda da Capitania de Minas operou até 1832/33 e em julho de 1833 a província inaugurou seu primeiro exercício fiscal sob novo sistema. 4

Neste artigo apresentamos a evolução de três dos principais títulos da receita colonial em Minas Gerais: os direitos de entrada, taxa sobre as importações cobradas nos registros (pontos de alfândega seca); os direitos de passagem, taxas sobre a travessia de rios em barcas ou em pontes; e o dizimo sobre a produção mercantil; cobrada diretamente nas unidades produtivas. Não são aprofundados os diversos aspectos destes títulos no período colonial, mas sim suas vicissitudes a partir da Independência e suas consolidações na Regência e no Segundo Reinado. ${ }^{5}$ Os dízimos se transformaram na taxa de exportação; os direitos de entrada e de passagem foram recriados sob o título de taxas itinerárias. Estes impostos eram cobrados nas recebedorias, postos fiscais que herdaram as estruturas dos registros.

\section{Direitos de entrada}

Os direitos de entrada produziram grande rendimento à Junta da Fazenda de Minas até sua extinção em 1832. Eram cobrados em postos fiscais guarnecidos, localizados em pontos estratégicos dos caminhos, os registros. Incidiam sobre a importação de gado muar a $3 \$ 000$ réis por cabeça, inclusive gado eqüino; de gado bovino a $1 \$ 500$ réis por cabeça (taxa extinta em c.1800); de escravos a $3 \$ 000$ réis por cativo; de fazendas secas a $2 \$ 250$ réis por carga de duas arrobas; e de fazendas molhadas a $\$ 750$ réis por carga de duas arrobas ou por barril de líquidos. ${ }^{6}$ Uma importante 
MATOS, Raimundo José da Cunha. Corografia Histórica da Provincia de Minas Gerais. Vol. 2. Belo Horizonte: Itatiaia; São Paulo: EDUSP, 1981. p.308.

Veto explícito pela primeira vez na lei orçamentária geral de 24 de outubro de 1832, artigo 12.

9

0 território que viria ser conhecido como Triângulo Mineiro foi transferido da capitania de Goiás para Minas Gerais em 1816 e os registros ai localizados passaram para a jurisdição de Minas Gerais. Vide caso documentado por Ana Rosa Cloclet da Silva (Cf. De Comunidades a Nação: Regionalização do poder, localismos e construções identitárias em Minas Gerais (1821-1831). Almanack Braziliense, n.2, p.61-62, nov.2005). Cloclet da Silva localizou erroneamente o registro de Santana do Rio das Velhas em São Romão; aquele se situava na barra do rio das Velhas afluente do rio Paranaiba, o que gerou a confusão com o rio das Velhas mais famoso que faz barra no São Francisco.

\section{0}

Excetuam-se os registros de Itajubá e do Picu que cobravam respectivamente taxas de exportações municipais das vilas de Campanha da Princesa e Baependi e funcionaram até dezembro de 1833

11

Portaria de 11 de março de 1837.

12

Arquivo Público Mineiro, pp1/49, cx.16, doc.1, 6 de agosto de 1837.

13

Arquivo Público Mineiro, pp1/33, cx.221, doc.9, 18 de setembro de 1837. alteração foi a isenção do sal, o principal gênero de importação mineira, em 1821. A divisão entre fazendas secas e molhadas era a única distinção de qualidade das mercadorias. Sobre este fato, Cunha Matos observou que "os direitos das importações pagam-se por arrobas, quer seja brocado de ouro, quer tecido de calhamaço ou lã mais grossa."7

Até 1790, a receita dos direitos de entrada advinha principalmente do arremate por contratadores, que se encarregavam de fazer a cobrança. A partir de 1790, a Junta da Fazenda de Minas passou gradualmente a cobrar os direitos de entrada por administração direta e a extinguir os registros internos no entorno dos principais arraiais, permanecendo apenas os registros na fronteira da capitania.

A cobrança nos registros não foi alterada com a Independência e a cobrança foi regular até junho de 1832. No ano fiscal 1831/32 verificou-se o primeiro orçamento regular no plano geral do Império e as leis orçamentárias gerais seguintes definiram a esfera fiscal provincial por exclusão. Os impostos de importação foram definidos como privativos do fisco imperial, definição reforçada pelo Ato Adicional. ${ }^{8}$ Este foi o único veto explícito ao fisco das províncias e obstruiu a arrecadação da principal fonte de receita de Minas Gerais e de outras províncias.

A medida do governo geral evitava a bitributação dos gêneros importados destinados ao consumo em Minas Gerais e em outras províncias que comerciavam com o Rio de Janeiro através do território mineiro, como o Noroeste de São Paulo (região de Franca), o Sul de Goiás (atual estado de Goiás) e o Oeste de Mato Grosso (fronteiriço com Goiás). Além da sobretaxa às importações, o comércio destas localidades interiores com o Rio de Janeiro era onerado por elevados custos de transporte. Estes custos agravados pelo fisco geraram conflitos entre goianos e mineiros em relação à jurisdição do registro de Santana do Rio das Velhas na barra do dito rio com o rio Paranaiba. ${ }^{9}$

Cessada a cobrança de direitos de entrada, os registros mineiros foram extintos em julho de $1832 .{ }^{10}$ Após a instalação da Assembléia Provincial, os deputados provinciais de Minas Gerais cogitaram a ressurreição dos registros. 0 presidente da província encaminhou às câmaras municipais uma portaria sobre o assunto. ${ }^{11}$ Recuperamos as respostas da edilidade de duas vilas. São gritantemente notáveis as diferenças entre as respostas de São Romão e Pouso Alegre.

A câmara de São Romão apreciava a resolução, que significaria "aumento das rendas provinciais", recuperaria taxas "de fácil arrecadação" e por "pagar o rico em proporção ao pobre", entendendo ser conveniente o restabelecimento dos registros no norte da província. ${ }^{12}$ São Romão era município interior, no Norte de Minas, de comércio fluvial (rio São Francisco), cujo único antigo registro em seu termo (Malhada) se situava mais de 200 quilômetros ao norte, na fronteira com a Bahia.

Já Pouso Alegre era município fronteiriço, no Sul de Minas, com mais ligações comerciais diretas com os portos, cujos três antigos registros percebiam razoável arrecadação (Jaguari, Campanha de Toledo e SapucaiMirim) devido ao trânsito das mulas importadas de Sorocaba. Segundo os oficiais da câmara de Pouso Alegre:

A nova criação dos registros não dará os rendimentos que se esperam, pelos muitos e enormes abusos que se praticam em tais estabelecimentos [...] e os povos se levantarão contra eles muitos clamores com a recordação do muito que sofreram e com a idéia de que têm de sofrer. ${ }^{13}$ 
Arquivo Público Mineiro, pp1/33, cx.221, doc.9, 18 de setembro de 1837.

15

Regulamento n¹5, anexo à lei n¹54 de 9 de abril de 1839. Em 1840, havia 23 recebedorias ativas, das quais 18 eram antigos registros reativados (um continuava desprovido por falta de funcionários) e apenas cinco eram novos postos fiscais.

\section{6}

Minas Gerais. Relatorio apresentado ao ill.mo e ex.mo snr. coronel Joaquim Camillo Teixeira da Motta, vice-presidente da provincia de Minas Geraes, pelo Inspector da Meza das Rendas, Affonso Celso Assiz Figueiredo, em 16 de julho de 1862. Ouro Preto: Typ. de Silva, 1862, mapas 1 e 8 A.

\section{7}

Arquivo Público Mineiro, pp 1/40, cx.36, docs.511; Arquivo Público Mineiro, pp 1/33, cx.54 docs.42-44; Arquivo Público Mineiro, pp 1/33, cx.55, docs.53-88.
Apesar do repúdio aos registros, a câmara de Pouso Alegre respondeu detalhadamente ao questionário, recomendando onde instalá-los "quando se julguem convenientes tais estabelecimentos reprovados pela maioria dos habitantes do municipio."14

A lei orçamentária do exercício de 1839/40 restabeleceu os registros em Minas Gerais, com o nome de recebedorias. ${ }^{15}$ Estes postos fiscais ficaram imediatamente responsáveis por cobrar a taxa de bestas novas, sobre a importação de gado muar, e posteriormente pelas taxas itinerárias, uma taxa de barreira sobre o trânsito interprovincial (reedição dos direitos de passagem) e que incluiam implicitamente um imposto de importação (reedição dos direitos de entrada). Depois de 1850, as leis de consolidação da receita provincial de Minas Gerais demonstravam a receita da taxa de bestas novas como uma modalidade de taxas itinerárias, pois ambas incidiam sobre o trânsito de animais.

\subsection{Taxa de bestas novas}

A criação da taxa sobre bestas novas em 1839, a $5 \$ 000$ réis por cabeça, representou o retorno de uma modalidade dos direitos de entrada, os direitos de $3 \$ 000$ réis por eqüídeo importado. Apesar de ser um direito sobre as importações, a taxa de bestas novas não gerou controvérsias com o fisco imperial, pois não incidia sobre os gêneros taxados nos portos e, portanto, não gerava bitributação com o fisco imperial.

Para o importador mineiro, a taxa de bestas novas era o terceiro imposto incidente sobre a importação de mulas. No caminho para Minas Gerais, o gado muar pagava taxas de $1 \$ 000$ réis à província do Rio Grande e de $3 \$ 500$ réis à de São Paulo, para um total de $9 \$ 500$ em taxas pagas por cabeça de gado muar entrado em Minas. 0 acúmulo de impostos de importação protegia a criação mineira, porém, as mulas "crioulas" (mineiras) não eram consideradas tão fortes e resistentes e não substituiam os animais importados. Além disso, os baixos custos da pecuária extensiva do sul do país permitiam que seus animais suportassem as sucessivas taxas.

Com o aumento da demanda mineira por mulas de Sorocaba na década de 1850 (até 25 mil animais anuais), a taxa de bestas novas se tornou importante fonte de renda da província, quase $10 \%$ da receita no decênio fiscal 1850-60.16 Sua importância para o orçamento provincial suscitou esforços para evitar o contrabando. São inúmeros os relatos de improbidade fiscal e os processos da Inspetoria da Mesa das Rendas contra administradores nas recebedorias na fronteira paulista, as quais faziam vista grossa ou participavam ativamente do descaminho das mulas. ${ }^{17}$

Por exemplo, o "encarregado pela Mesa das Rendas Provinciais da Fiscalização de Bestas Novas no ano de 1852" cobrou justificação do capitão Francisco Ribeiro da Luz pela introdução de 148 bestas que o mesmo "trouxera e que vendia no município de Cristina e vizinhos". Na inquirição de testemunhas residentes na margem da estrada, buscou-se averiguar "se a tropa passou em alguma Recebedoria sem pagar imposto" ou "se o justificado havia passado por algum extravio com fazer da noite, ou abriu alguma picada para entrar a tropa". 0 fiscal queria saber se 0 contrabandista agira independentemente, ou se houvera conivência dos agentes responsáveis pela cobrança da taxa em alguma das recebedorias limitrofes. Uma peculiaridade deste caso é o fato de o contrabandista de 1852 ser primo do futuro Inspetor da Mesa das Rendas Provinciais (1855) 
18

"Justificação de divida. Justificante: 0 Alferes Antonio de Sá Pessoa - encarregado pela Mesa das Rendas Provinciais. Justificado: 0 Capitão Francisco Ribeiro da Luz." (Cristina/MG, 28 de agosto de 1852. Centro de Documentação e Memória, Fundo Juizo Municipal, cx.89, doc s.n.).

\section{9}

Arquivo Nacional do Rio de Janeiro, Casa dos Contos, cód.1237, fl.86v.

\section{0}

Ibidem, cód.1237, fl.90.

\section{1}

Segundo o Intendente da Comarca, "os donos de tropas de bestas novas e todos os mais gêneros que devem pagar os Direitos fazem consideráveis prejuizos" ao extraviarem os direitos do registro de Itajubá, e "porque sendo o registro situado em lugar ermo são as entradas de caminhos as mais perigosas e dificeis têm os tropeiros largado as Estradas Gerais" e para compensar sua pequena comissão "tem o Comandante cobrado para sairem das Grandezas de seu Registro e se fazem tudo em prejuizo dos Reais direitos" e conclui que este oficial "já perdeu aquele antigo brio e força com que se empregara no Real serviço querendo com autoridade de comandante desse Registro proteger por modos sinistros os particulares [...]" (ofício de Joaquim José Soares de Araújo, Intendente da Comarca do Rio das Mortes. São João Del Rei, 17 de agosto de 1805. Arquivo Nacional do Rio de Janeiro, Casa dos Contos, cód.1237, fl.142).

22

Ordem de Pedro Maria Xavier de Ataide e Melo, governador e capitão-general da Capitania de Minas Gerais e presidente da Junta da Real Fazenda da mesma. Vila Rica, 26 de agosto de 1805. Arquivo Nacional do Rio de Janeiro, Casa dos Contos, cód.1237, fl.140. Nesta época, cada mula pagava adicionalmente à taxa do subsídio voluntário a $1 \$ 200$ réis por cabeça. Ou seja, o guarda-mor Nogueira extraviou $915 \$ 600$ réis.

23

Para a maioria destes grandes importadores a suspeição é corroborada pelos seus padrões de trânsito, por exemplo, pela recorrência de quantias múltiplas de quatro. 0 caso de Francisco Xavier Martins é típico: pagava anualmente direitos para dezenas de bestas novas, mas em uma ocasião pagou por 690 cargas de sal, equivalentes a 173 animais, na que teria sido sua maior importação de mulas. e Presidente da Província (1859), o senador e conselheiro Joaquim Delfino Ribeiro da Luz. ${ }^{18}$

A fraude era facilitada pela própria natureza do objeto tributável, que era o meio de transporte usual do comércio interprovincial. Enquanto mulas de tropa com cangalhas descarregadas não fossem consideradas bestas novas, importadores espertos adestravam primariamente as mulas xucras adquiridas em Sorocaba e botavam-Ihes cangalhas para passarem por animais de tropa, ou mesmo carregavam-nas para dar maior veracidade. Este tipo de fraude era conhecido desde os tempos em que a taxa de importação de mulas era uma modalidade dos direitos de entrada. As seguintes cobranças foram escrituradas no livro do registro de Itajubá em agosto de 1804 e julho de 1805 :

Passou o Comandante deste Registro o Porta-estandarte Mariano Ferreira da Silva 8 cargas de sal em 2 bestas novas que comprou para sua condução... a \$750 [por carga de molhados]... $6 \$ 000$ réis. [assinam o próprio e o administrador Felix José de Siqueira]. ${ }^{19}$

0 Guarda-mor José Martins Nogueira morador no Termo da Vila de Cunha Capitania de São Paulo com 872 cargas de sal que passou em 218 bestas carregadas a 4 cargas cada uma, a $\$ 750 \ldots 654 \$ 000$ rs. [assinam o comandante e o administrador]. 20

Estas não eram escriturações típicas deste livro contábil (cujos termos de abertura e de encerramento datam de 1792 e 1810). Foram as únicas ocasiões em que os fiéis do registro informaram os animais empregados na condução das fazendas taxadas. Note-se que os direitos incidentes sobre a carga completa de um animal (quatro cargas molhadas a $\$ 750$ rs.) eram os mesmos que se pagava por uma besta nova ( 3000 rs.), mas em ambos os casos cobrou-se apenas a taxa sobre as fazendas molhadas. 0 primeiro caso não suscitou reclamações, talvez configurasse exceção prevista no regulamento dos registros - importação do comandante para suprimento do quartel do registro de Itajubá. Já o segundo caso gerou um processo para verificar a responsabilidade do administrador e do comandante do registro21 e culminou na expulsão do último:

Faço saber o Intendente da Comarca do Rio das Mortes que na Junta da minha Real Fazenda desta Capitania foi presente o abuso em que estão alguns dos Fiéis dos Registros permitindo contra os meus Reais interesses aos viandantes passarem bestas novas livres dos Direitos e Subsidio a pretexto de alguma carga que com todo o escândalo se Ihes põem nas vizinhanças dos Registros como sucedeu no do Itajubá com duzentas e dezoito bestas interpretando a seu gosto as ordens com manifesta fraude da Real Fazenda no que sendo ouvido o Desembargador Provedor da mesma fazenda sou servido ordenar-vos que façais executar nos Registros da vossa inspeção as ordens tendentes a semelhantes arrecadadores [...] na inteira observância das mesmas ordens para informareis logo que alguém for compreendido na sua falta a fim de ser expulso do seu lugar como indigno de se empregar no meu Real serviço. 22

Este caso só veio à tona porque o contrabandista pagou direitos por uma quantidade tão grande de sal que os próprios fiéis do registro denunciaram o extravio na escrituração irregular dos direitos de entrada. Enquanto as maiores tropas de bestas arreadas tinham no máximo cerca de uma centena de animais, todos os direitos pagos por importadores de mais de 400 cargas de sal seriam suspeitos de extraviarem bestas novas. ${ }^{23}$ 
24

Determinação do Inspetor da Tesouraria Provincial Domingos de Andrade Figueira em 20 de setembro de 1868 (apud RIBEIRO, Joaquim Cypriano. Roteiro dos Exactores da Fazenda Provincial de Minas Gerais. [Ouro Preto]: Typ. do Diario de Minas, 1876. p.250).

25

Leis mineiras $n .12$ de $1835, n .73$ de 1836 e $n .74$ de 1836.

26

Lei mineira n.78 de 1837. As barreiras da estrada do Paraibuna funcionaram conforme o regulamento n.14 de 1838. Em 1840 foi criada uma quarta barreira, na recebedoria do Presídio.

27

Lei mineira n.234 de 25 de novembro de 1842.

28

DOLHNIKOFF, Miriam. Entre o centro e a província: as elites e o poder legislativo no Brasil oitocentista. Almanack Braziliense, n.1, p.88, mai.2005, p.88.
Ainda em 1868 o inspetor da Mesa das Rendas alertava aos administradores das recebedorias que "a besta não deixa de ser nova porque o dono ou condutor procurou amansá-la em caminho, ou para esse fim demorou antes de passar pela recebedoria, como parece ao Dr. Procurador Fiscal."24 Os importadores reclamavam ao Procurador Fiscal que eram lesados pelo fisco, pois pagavam à taxa para bestas não eram xucras, e a legislação, o próprio nome da taxa, dava a entender que o imposto incidia tão-somente sobre mulas xucras. Todavia, a redação da lei passou a estipular que quaisquer mulas, xucras ou não, que fossem novas em Minas deveriam pagar a taxa.

A cobrança da taxa de bestas novas permaneceu sem qualquer mudança até o fim do Império, mesmo durante a década de 1880, quando as importações médias foram inferiores a mil cabeças por ano.

\subsection{Taxas itinerárias}

Os direitos de passagem da capitania foram precursores das taxas de barreira da Província. E os direitos de entrada das importações foram recriados em Minas Gerais através de modalidades especificas de taxa de barreira.

Os direitos de passagem incidiam sobre o serviço de transporte sobre rios ou utilização de pontes em registros de fronteira ou em portos internos. Era uma taxa sobre o trânsito, um pagamento ao serviço prestado, ou seja, uma taxa de barreira, um pedágio.

A lei orçamentária geral de 24 de outubro de 1832 definiu a esfera fiscal do Império e uma vez que os direitos de passagem não constaram da arrecadação geral, as províncias podiam aplicar este título em sua receita. As províncias perceberam o potencial dos direitos de passagem na cobrança de taxas sobre o serviço de conservação das vias. Na segunda metade da década de 1830, algumas províncias criaram barreiras, postos fiscais similares aos registros, para a cobrança de pedágio (taxa de barreira), como Rio de Janeiro e São Paulo.

Em Minas Gerais, as receitas dos direitos de passagens de rios consolidadas dos exercícios de 1833/34, 34/35 e 35/36, representaram respectivamente $41,7 \%, 32,1 \%$ e $27,6 \%$ da arrecadação provincial, constituindo o principal título da receita. ${ }^{25}$ Este título permaneceu como importante fonte de receita até 1845/46. A partir de 1846/47 a arrecadação de direitos de passagem em portos internos foi transferida para a esfera municipal (sob administração direta ou delegada a contratadores), restando à esfera provincial a cobrança dos direitos nas vias interprovinciais, como taxa de barreira, sob o título de taxas itinerárias.

A primeira taxa de barreira da província mineira entrou em vigor no ano fiscal 1838/39. Com a reconstrução da estrada do Paraibuna, entre Barbacena e a divisa com o Rio de Janeiro, criaram-se três barreiras cujas receitas teriam aplicação especial para a conservação da estrada. ${ }^{26}$ Novas taxas de barreira com o caráter de pedágio seriam criadas apenas em 1846.

A lei orçamentária provincial para o exercício de 1843/44 instituiu uma taxa de barreira pouco convencional em todas as recebedorias da fronteira mineira. ${ }^{27}$ Não era um pedágio de incidência geral sobre 0 trânsito, mas uma taxa cujo objeto tributável era bastante específico: a lei estipulou o pagamento de $4 \$ 000$ réis por animal que entrasse em Minas Gerais transportando gêneros que não fossem produzidos em províncias limitrofes, sob o título de direitos de entrada. ${ }^{28}$ 
29

DOLHNIKOFF, Miriam. Entre o centro e a provincia: as elites e o poder legislativo no Brasil oitocentista. Almanack Braziliense, n.1, p.88, mai./2005, p.88.

30

Ibidem, p.88
Lei mineira n.310 de 8 de maio de 1846. Antes, a lei n.306, capítulo $3^{\circ}$, definira as rendas de aplicação especial para o ano 1846/47 e, no artigo $4^{\circ}$, estabelecera taxas itinerárias fixas nas recebedorias na fronteira fluminense.
Os direitos de entrada de 1843 não deveriam ser entendidos na acepção colonial do termo. Se a taxa incidia sobre os animais, e não diretamente sobre os gêneros, então não era um imposto de importação. Por outro lado, o oneroso pedágio incidia unicamente sobre animais que transportavam mercadorias importadas do estrangeiro ("gêneros de províncias que não fossem limítrofes"). Para estes gêneros, o novo direito de entrada era a reprodução do antigo, a taxas mais suaves. Antes, cobravam-se $2 \$ 250$ réis por duas arrobas de fazendas secas, ou $9 \$ 000$ por animal com oito arrobas de mercadorias importadas; agora, cobravam-se $4 \$ 000$ réis por animal carregado. Em ambos os casos, os direitos eram cobrados por peso, sem distinção de qualidade: parafraseando Cunha Matos, pagavam por carga, quer fosse brocado de ouro, quer fosse lã da mais grossa.

A taxa de importação de gêneros estrangeiros foi arrecadada nas recebedorias de Minas Gerais sob o título de direitos de entrada entre outubro de 1843 e junho de 1846 . E continuou sendo cobrada de julho de 1847 até o fim do Império, não mais sob aquele infeliz título, mas propriamente camuflada como taxa de barreira.

Os novos direitos de entrada reproduziram antigas querelas, pois invadiam tanto a esfera fiscal geral, ao bitributarem importações, quanto a de outras províncias, ao onerarem o comércio de províncias interiores que utilizavam o território mineiro na comunicação com o Rio de Janeiro. Em 1845, os deputados mineiros enfrentaram processo de revogação dos direitos de entrada na Assembléia Legislativa Geral:

Posicionaram-se contra a lei mineira os deputados do Mato Grosso e Goiás, uma vez que suas províncias consumiam grande quantidade de produtos vindos do Rio de Janeiro, que necessariamente passavam por Minas e, em razão do imposto ali cobrado, chegavam ao mercado final com considerável aumento de preço. 29

Os direitos de entrada eram de fato inconstitucionais, pois impostos de importação eram vedados à receita provincial. Segundo Miriam Dolhnikoff, a pressão dos goianos e mato-grossenses surtiu efeito: "os deputados mineiros não tiveram sucesso [na defesa dos direitos de entrada], pois a lei de Minas acabou sendo revogada". 30 De fato, não houve cobrança de direitos de entrada em Minas Gerais no ano fiscal 1846/47. Mas os mineiros recriaram estes direitos no ano seguinte, com uma lei cuja redação não dava margem a interpretações que os qualificassem como imposto de importação, mas tão-somente como taxa de barreira. Se a cobrança de direitos especiais sobre animais com mercadorias estrangeiras era tipificada como imposto de importação e considerada inconstitucional, então a cobrança dos direitos de valor mais elevado sobre todos os animais em trânsito só poderia ser tipificada como taxa de barreira, imposto privativo da esfera provincial e não-conflitante com o fisco de outras províncias.

A primeira etapa para a sedimentação dos direitos de entrada como taxa de barreira foi a própria recriação desta taxa com caráter de pedágio. A lei orçamentária para 1846/47 mandou dividir as estradas em provinciais (interprovinciais) e municipais (intermunicipais). 0 exercício de 1846/47 foi o primeiro em que vigoraram as taxas itinerárias, direitos de barreira com receita de aplicação especial, ou seja, para a conservação das vias interprovinciais. ${ }^{31}$ A segunda etapa foi a inversão da nova taxa geral (direitos de barreira com caráter de pedágio) com a antiga taxa de 
32

Portaria de 9 de junho de 1847. 0 sal, um dos principais artigos de importação mineira, já era isento do pagamento de direitos de entrada desde 1821.

33

Confirmando a similitude da taxa itinerária "geral" com os antigos direitos de entrada, a cobrança podia ser feita por cargas, pagando-se pelas importações de "meio animal". Em algumas recebedorias, a arrecadação anual consolidada totalizou somas quebradas.

34

Conforme a lei de orçamento de $1^{\circ}$ de dezembro de 1873, artigo $1^{\circ}, \$ 21$, carros com capacidade de conduzir até 50 arrobas pagavam $19 \$ 200$ réis; de 50 a 100 arrobas, $24 \$ 000$ réis; de 100 a 150 arrobas, $36 \$ 000$ réis; de 150 a 200 arrobas, $48 \$ 000$ réis; de 200 a 250 arrobas, $60 \$ 000$ réis; de 250 a 300 arrobas, $72 \$ 000$ réis (RIBEIRO, Joaquim Cypriano. Roteiro dos Exactores da Fazenda Provincial de Minas Gerais. [Ouro Preto]: Typ. do Diario de Minas, 1876. p.249).

\section{5}

Arquivo Público Mineiro, Biblioteca, Tabelas da Mesa das Rendas Provinciais, Vols. 3 e 3A; Arquivo Público Mineiro, Balanços e Orçamentos Apresentados à Assembléia Legislativa Provincial no ano de 1859; Idem, 1861.

\section{6}

Contrato de 31 de janeiro de 1853, apud ESTEVES, Albino de Oliveira. Mariano Procópio. Revista do Instituto Histórico Brasileiro, Vol.230, p.17-18, Jan-Mar de 1956. 0 contrato previa que entre 1854 e 1857 a União e Indústria haveria metade do produto das taxas, deduzidas as despesas de arrecadação. No entanto, arrecada-

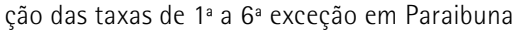
nestes anos foi deixada em branco (Arquivo Público Mineiro, Biblioteca, Tabelas da Mesa das Rendas Provinciais, Vol. 3; Arquivo Público Mineiro, Balanços e Orçamentos Apresentados à Assembléia Legislativa Provincial no ano de 1859) exceção (direitos de barreira diferenciados para animais e carros carregando importações) para o exercício de 1847/48.

A solução mineira veio com a própria redação da lei. A antiga taxa diferenciada se tornou a regra geral e as taxas de pedágio instituídas no ano anterior se tornaram as regras de exceção. A lei n³29 que orçou a receita de 1847/48 estabeleceu em seu capitulo $3^{\circ}$, artigo 4ㅇ, que se arrecadassem nas recebedorias:

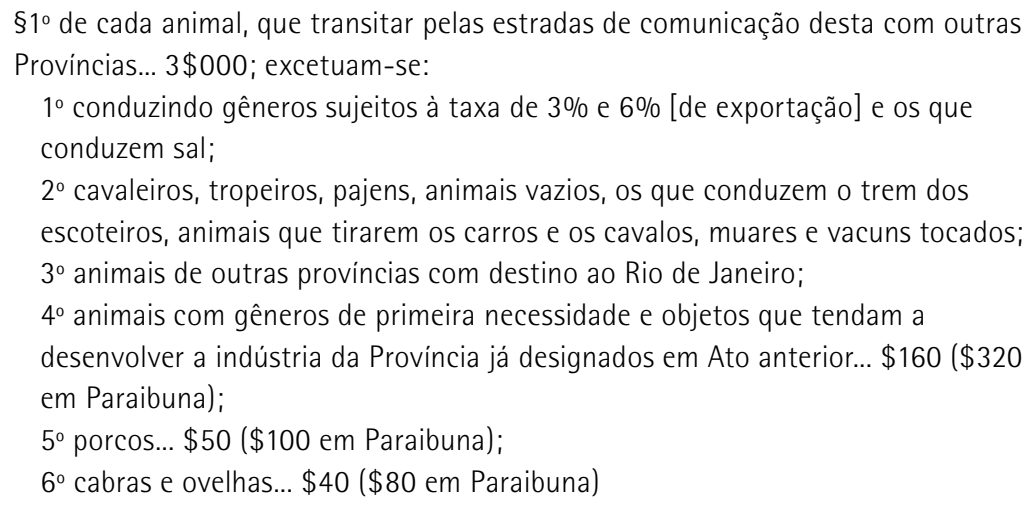

$\S 2^{\circ}$ de cada carro... $19 \$ 200$ exceto carregados de gêneros das exceções do parágrafo anterior... $1 \$ 000$ (2\$000 em Paraibuna)

As taxas itinerárias gerais, cobradas a $3 \$ 000$ réis por animal (parágrafo primeiro) e 19\$200 réis por carro (parágrafo segundo), eram pagas pelos animais e carros "não excetuados". Pagavam muito menos os animais e carros nas exportações, no transporte pessoal e com gêneros importados considerados essenciais, os animais empregados na condução de carros e todos os gados soltos. Pagavam à taxa geral tão-somente os animais e carros com importações não constantes da $4^{a}$ exceção; os "gêneros de primeira necessidade" referidos nesta exceção eram sal, máquinas e instrumentos agrícolas. 32

A redação das taxas itinerárias de 1847/48 foi mantida até 1881 com poucas modificações. A taxa geral sobre animais foi elevada a $3 \$ 920$ réis a partir de $1850 / 51$ e a $4 \$ 500$ desde $1876 / 77.33$ A taxa geral sobre carros passou a distinguir os mesmos por capacidade de carga, em categorias de $19 \$ 200$ a $41 \$ 400$ réis a partir de 1850/51, e desde 1867/68 foram definidas novas categorias de carros que pagavam de $48 \$ 000$ a $72 \$ 000$ réis. ${ }^{34}$

As taxas itinerárias compunham uma importante parcela da receita provincial, 22\% do total em 1850-60.35 A proporção seria ainda maior, pois a partir de janeiro de 1854 a receita das taxas da $1^{\text {a a }} 6^{\text {a }}$ exceção na recebedoria do Paraibuna foi transferida para a companhia União e Indústria ${ }^{36}$. Em 1850-52, os itens de exceção em Paraibuna representaram 15\% da arrecadação total das taxas itinerárias. Por outro lado, a arrecadação das taxas itinerárias não excetuadas (direitos de entrada) na recebedoria do Paraibuna continuou sob controle do fisco: as importações mineiras nas diligências da União e Indústria contribuíram enormemente para a arrecadação na forma de taxas gerais sobre carros (a 19\$200 ou mais, bem documentada para o período 1866-78).

Os direitos de entrada foram redefinidos em 1881. Com a expansão da malha ferroviária a partir da segunda metade da década de 1870, as importações passaram a penetrar o território mineiro sobre trilhos, dentro dos vagões, o que fez diminuir a arrecadação das taxas itinerárias. A 
37

Em Portugal, o dizimo foi estabelecido por bula do Para de 1455 com renda de aplicação especial para o pagamento dos ministros da Igreja. No Brasil, não havia vinculação direta da receita do dízimo com a administração eclesiástica (MATOS, Raimundo José da Cunha. Corografia Histórica da Província de Minas Gerais. Vol. 2. Belo Horizonte: Itatiaia; São Paulo: EDUSP, 1981. p.223-233)

\section{8}

Sobre os dizimos em Minas Colonial, ver CARRARA, Angelo Alves. Minas e Currais. Juiz de Fora: UFJF, 2007. p.253-271.

\section{9}

TESSITORE, Viviane. As Fontes da Riqueza Pública. 1995. Dissertação de Mestrado. Faculdade de Filosofia, Letras e Ciências Humanas, Universidade de São Paulo, São Paulo, 1995. p.149.

40

Ibidem, p.150.

41

Aviso régio de 6 de setembro de 1821.

\section{2}

VASCONCELOS, Bernardo Pereira de. "Parecer sobre o sistema tributário" (1828). Apud ESTEVES, Albino de Oliveira. Mariano Procópio. Revista do Instituto Histórico Brasileiro, Vol.230, p.100, jan-mar/1956.

43

A decisão do Ministério da Fazenda de 5 de novembro de 1832 mandou arrecadar dizimos de 5\% "sobre os gêneros de produção das Províncias nos Registros que os Presidentes estabelecerem nos portos secos por onde saem". A lei geral n58 de 8 de outubro de 1833 definiu em seu art. 31, §10 e \$11 que integrariam a renda geral direitos de $2 \%$ sobre o açúcar, café, algodão, tabaco e fumo, exportados para fora do Império, assim como o gado bovino e os cavalos; os demais pertenceriam à renda provincial. Finalmente, a lei de 31 de outubro de 1835 art. 9, §6, elevou aqueles $2 \%$ sobre a exportação da produção brasileira para 7\%, abatidos os 5\% que pagavam os gêneros de produção da Provincia nos registros, conforme a citada decisão ministerial de 5 de novembro de 1832. Cf. TESSITORE, Viviane. Op.Cit., p.150

\section{4}

Provisão da Junta da Fazenda de Minas Gerais de 11 de novembro de 1825 .

45

Arquivo Público Mineiro, pp 1/6, cx.1, doc.18. província criou taxas especificas sobre a entrada de mercadorias, incursões explícitas no campo dos impostos de importação. Tratava-se novamente de uma taxa geral por peso, sem distinção de qualidade. A cobrança por peso era obviamente mais eficiente do que a cobrança por carga de animal, pois comportava o pagamento das importações feitas nos vagões dos trens. A partir de 1881, cobravam-se 33 réis por quilo de carga importada. A taxa por peso era equivalente à antiga taxa por animal de carga. Transformando quinze quilos em uma arroba, e oito arrobas na carga de um animal, a taxa incidente sobre mercadorias importadas era de $3 \$ 960$ réis por carga.

\section{Dízimos e direitos de exportação}

0 dizimo era um imposto sobre a produção agropecuária cuja origem remonta à Idade Média. ${ }^{37}$ No Brasil colonial, sua arrecadação era administrada conforme as condições locais de cada capitania. Quando administrado por arrematantes, os contratantes delegavam seus próprios métodos de cobrança. Na capitania de Minas Gerais, o dizimo incidia sobre a produção mercantil. Era arrecadado por arrematantes, mas não havendo licitantes, ou se insatisfatório o valor do lance, a Junta da Fazenda administrava diretamente. Era recolhido diretamente nos centros produtores por meio de avenças (tributação sobre a produção futura). ${ }^{38}$

A arrecadação dos dízimos foi reestruturada a partir do decreto de 16 de abril de 1821 que definiu seu recolhimento a cargo da Administração Geral "na entrada de vilas, arraiais e povoações", ou seja, em registros de alfândega seca. 390 novo perfil do dízimo foi reforçado pelo decreto de 21 de maio de 1825, que mandou cobrá-lo especificamente na exportação para fora do Império. 40 Em Minas Gerais, a arrecadação nos locais de produção continuou permitida devido a dificuldades no cumprimento do decreto de 1821. ${ }^{41}$ Conforme um "parecer sobre o sistema tributário" de 1828 do futuro senador mineiro Bernardo de Vasconcelos, ambos os decretos de 16 de abril de 1821 e 21 de maio de 1825 não foram executados em Minas. ${ }^{42}$

Enquanto os dízimos de Minas Gerais sempre foram controlados pelo fisco provincial, as taxas de exportação tinham sido alocadas para a receita geral pelo decreto de 1821. A taxa de exportação das províncias litorâneas pertenceria a duas esferas fiscais: em 1832, entendeu-se que integravam o fisco provincial e seria cobrada nos registros; em 1833, sua receita nos portos foi repartida com o governo geral; e em 1835 definiu-se a partilha da taxa de exportação que seria mantida por décadas com poucas alterações. ${ }^{43}$

Em Minas Gerais, os dízimos continuaram sendo arrecadados por meio de avenças nas unidades produtivas até 1839. Ou seja, o exportador mineiro lidou com dois sistemas de arrecadação. Para evitar a bitributação, emitia-se em Minas um comprovante de pagamento. Em 1825, os registros mineiros na fronteira com o Rio de Janeiro receberam livros para o "lançamento das guias do dízimo de café e algodão".44 As autoridades mineiras alertavam que todo "açúcar, algodão em rama, arroz, café, fumo e farinha de trigo" exportado sem a respectiva guia pagaria os dízimos no Rio de Janeiro. 45

Teoricamente, o dízimo cobrado na produção incidia sobre maior número de objetos tributáveis do que o dízimo cobrado na exportação, pois se presume que todas as mercadorias comercializadas para fora de qualquer termo administrativo foram antes dizimadas no local de produção. Entretanto, a arrecadação dos dízimos por meio de avenças era 
46

Arquivo Público Mineiro, pp 1/36, cx.19, doc.22, novembro de 1833.
47

Regulamento $n^{\circ} 7$ de 13 de julho de 1836 que dispõe sobre a arrecadação do dízimo no exercicio de 1836/37. muito menos eficiente do que a cobrança nos registros e/ou nos portos. Por exemplo, em São Paulo todas as exportações mineiras estavam sendo tributadas, pois nenhuma acompanhava guia de pagamento do dízimo:

Os Condutores de Tropas que conduzem gêneros dessa Província [São Paulo] e passam pelo Registro da Boa Vista [Pindamonhangaba/SP], não trazem Guia, ou Documento algum, por onde consta serem os gêneros de produção dessa Província. Levo à consideração de V.E. o inconveniente representado da qual pode resultar nada menos do que serem exportados os gêneros desta Província (Minas Gerais) como produtos dessa. 46

Alguns trechos do regulamento dos dízimos de Minas Gerais ilustram as dificuldades da cobrança por meio de avenças e da emissão de guias comprobatórias vis-à-vis a percepção nos registros como taxa de exportação:

Artigo $2^{\circ}$. A importância de $5 \%$ ou $10 \%$ será toda paga a dinheiro: e o pagamento será feito no ano posterior ao da colheita, em duas prestações semestrais que se verificam nos meses de junho e dezembro, nos lugares de residência dos coletores $[\ldots]$

Artigo $5^{\circ}$. Os coletores, tendo anteriormente procurado haver todas as informações circunstanciadas a respeito do estado das fazendas, lavouras e criação de cada um dos habitantes de seu distrito, e dos valores dos gêneros sujeitos aos 5\% ou 10\% nos lugares em que estiverem, irão pelas habitações dos fazendeiros, lavradores e criadores tomar as declarações e fazer os arbitramentos de que há de apurar o lançamento; [...]

Artigo $12^{\circ}$. Quando alguns dos gêneros sujeitos ao pagamento dos $5 \%$ ou 10\% forem levados desta para outra província, serão acompanhados de guias qualificativas de sua origem, que certifiquem serem os mesmos gêneros [...] a fim de que, à vista de tais guias, que nos registros da província do Rio de Janeiro têm de ser verificadas e anotadas, sejam isentos do pagamento da cota pertencente a ela $[\ldots]$

Artigo $13^{\circ}$. Estas guias serão passadas em nome dos coletores dos distritos donde sairem os gêneros, e por eles assinadas no formato do Modelo $n^{\circ} 4$ e serão lançadas em registro [...] e para conferir com igual relação, ou mapa dos gêneros desta província, entradas nos registros [...] que serão requisitados do governo da província do Rio de Janeiro. 47

0 sistema fiscal de Minas Gerais tentava compatibilizar-se com o sistema do Rio de Janeiro. Pelo lado fluminense, temia-se a formação de um "mercado de guias do dízimo de Minas" que prejudicaria sua arrecadação. A presidência fluminense proveu de fiscais os antigos registros mineiros na sua fronteira, a fim de fiscalizar as exportações de Minas Gerais e passar-Ihes guias da sua província para as mercadorias mineiras que não portassem comprovante de origem. Pelo lado mineiro, o procurador fiscal notou que o regulamento dos dízimos não estava sendo cumprido. A maior parte dos gêneros remetidos para o Rio de Janeiro não era dizimada, pois os exportadores não se davam ao trabalho de retirar a respectiva guia na coletoria municipal:

0 Regulamento 7 - Artigo 12 - dispõe que os gêneros de exportação sujeitos ao dizimo de $5 \%$ e $10 \%$ vão acompanhados de guias qualificadas de sua origem, e identidade para serem isentos de novo pagamento. A não ser assim, extraviam-se 
48

Arquivo Público Mineiro, pp 1/14, cx.68, doc.35, Ouro Preto, 27 de setembro de 1836, Antonio Ribeiro Andrade, Procurador Fiscal.

49

Ibidem. Registro do Rio Preto, 31 de julho de 1836, Antonio José Ozório Leitão, Administrador.

50

Ibidem, Registro da Paraibuna, 6 de agosto de 1836, Amador de Lemos Ornellas, Administrador.

51

Ibidem, Registro da Mantiqueira provisoriamente em Lava-pés na Vila de Resende, 9 de setembro de 1836, Luiz José da Rocha, Administrador.

52

Ibidem, $1^{\circ}$ de outubro de 1836, Joaquim Dias Bicalho, Inspetor da Mesa das Rendas Provinciais.

53

0 regulamento $n^{\circ} 11$ de 26 de junho de 1837 que dispôs sobre a arrecadação do dízimo no exercício de 1837/38 seguiu em geral o regulamento anterior, com mudanças nos arbitramentos e sem menção à exportação (vide artigos 12 e 13 do regulamento $\left.n^{\circ} 7\right)$. os gêneros, e a Fazenda Provincial sofre perda nos seus impostos. [...] Pelas participações que se juntam [em anexo] colhe-se [...] que os gêneros que passam nos Registros postos pela Corte não vão acompanhados de guia de Coletores desta Provincia, ou porque ficam muito distantes, ou porque não têm ali Agentes, e mesmo antes querem pagar no Rio, que tomar o trabalho de procurar os Coletores. $^{48}$

0 procurador fiscal anexou ao seu ofício os relatos dos administradores fluminenses dos registros do Rio Preto, Paraibuna e Mantiqueira. Estes documentos atestavam a passagem de gêneros mineiros sujeitos ao dízimo, especialmente café, tabaco e açúcar, nos meses de julho a setembro de 1836, mas que raramente eram acompanhados das "guias conforme o modelo":

Ao café nenhuma guia tem acompanhado, e os Tropeiros de quem as exijo respondem-me que seus Patrões não costumam dar-Ihes guias. Algum fazendeiro me tem apresentado a dificuldade e incômodo que lhes causa o manda-la buscar à Vila de Barbacena, onde reside o Coletor, na distância de 20 e mais léguas. Alguns têm mesmo exigido que eu lhes passe; o que me tenho escusado, por não ter para isso autorização. Têm-me sidas também apresentadas algumas Atestações passadas pelo Juiz de $\mathrm{Paz}$, as quais não tenho conferido, nem registrado, não só porque não têm vindo acompanhadas do Café, como por não serem as guias de que trata o meu Regulamento. 49

Até esta data não tenho verificado Guia alguma posto que tenha efetivamente aqui passado gêneros sujeitos ao imposto do dízimo, mormente Café, e açúcar, e perguntando aos Condutores por as Guias, e fazendo-Ihes ver o que me ordena o artigo $5^{\circ} \$ 3^{\circ}$ do Regulamento dos Registros do Rio de Janeiro, dizem-me que por se the terem inutilizado já algumas guias na Corte antes queriam ir pagar lá do que em sua Província; e outros finalmente me afirmam quererem antes pagar no Rio de Janeiro do que mandar a imensas léguas a receber Guias, pois que daqui da Ponte do lado daquela Província já principia haver exportações de Cafés, para esta. 50

No Registro da Mantiqueira o problema era idêntico. Foram exportadas 4.576 arrobas de fumo mineiro tão-somente em agosto de 1836, mas "nenhum passou acompanhado de guia", pois os tropeiros "preferem pagar 3\% no Rio de Janeiro". Em julho haviam sido recolhidas sete guias que somavam apenas 983 arrobas e reclamava-se do contrabando. ${ }^{51} 0$ problema foi reconhecido pelo inspetor das Rendas Provinciais de Minas Gerais:

Nenhum condutor haverá que queira pagar 10\% do café nesta província, podendo na do Rio de Janeiro pagar somente $3 \%$, como dispõe o Regulamento de 26 de Maio deste ano em execução da Lei n ${ }^{\circ} 6$ da Província do Rio de Janeiro [...] As razões, que venho de expor serão talvez o motivo de os Tropeiros não procurarem Guias nas respectivas Coletorias. ${ }^{52}$

Por conta da menor alíquota no Rio de Janeiro, os dízimos do café, tabaco, algodão, açúcar e rapaduras foram reduzidos de 10\% para $3 \%$ no ano financeiro 1837/38.53 0 alívio fiscal deve ter surtido efeito, pois não se encontram mais reclamações.

Finalmente, a lei mineira nº154 de 9 de abril de 1839, que orçou a receita de 1839/40, determinou que "fica extinto o imposto do dizimo" e estabeleceu a taxa de exportação em Minas Gerais, para ser cobrada nas recebedorias criadas pela mesma lei. Foi definida uma pauta de preços a partir da qual se arrecadariam "3\% do café, açúcar, tabaco, algodão e de quaisquer gêneros manufaturados que se exportarem" e "6\% de todos os 


\section{4}

Minas Gerais. Relatorio apresentado ao ill.mo e ex.mo snr. coronel Joaquim Camillo Teixeira da Motta, vice-presidente da provincia de Minas Geraes, pelo Inspector da Meza das Rendas, Affonso Celso Assiz Figueiredo, em 16 de julho de 1862. Ouro Preto: Typ. de Silva, 1862, mapas 1 e 8 A.

\section{5}

As providências paulistas são bem descritas por Viviane Tessitore (Cf. TESSITORE, Viviane. As Fontes da Riqueza Pública. 1995. Dissertação de Mestrado. Faculdade de Filosofia, Letras e Ciências Humanas, Universidade de São Paulo, São Paulo, 1995. p.157-158).

\section{6}

Arquivo Público Mineiro, fp, enc.22, p.280, 2 de setembro de 1844

\section{7}

Arquivo Público Mineiro, pp1/36, cx.20, doc.61, 24 de novembro de 1846.

58

Arquivo Público Mineiro, pp1/36, cx.20, doc.67, 18 de setembro de 1847 .

59

Rio de Janeiro. Relatorio do presidente da provincia do Rio de Janeiro, o senador Aureliano de Souza e Oliveira Coutinho, na abertura da Assembléa Legislativa Provincial no $1^{\circ}$ de março de 1846. 2a edição. Nictheroy: Typographia de Amaral \& Irmão, 1853. p.7-10. gêneros de produção e criação da Província, que forem exportados". A taxa de exportação passaria a ser a principal fonte de receita da província de Minas Gerais, respondendo por 26\% do total arrecadado em 1850-60.54

Os preços de referência da taxa de exportação de Minas Gerais eram muito inferiores aos preços de mercado, o que suscitou nos fiscos do Rio de Janeiro e São Paulo o temor de que seus exportadores comprassem guias falsas como se fossem de produção mineira. Ao mesmo tempo, esta desconfiança da legitimidade dos comprovantes de pagamento em Minas Gerais fez os mineiros temerem por suas guias não serem aceitas na alfândega do Rio de Janeiro. A possibilidade de bitributação estimularia os exportadores mineiros ao descaminho das recebedorias.

A maior preocupação era a evasão fiscal do café, que seria especialmente lesiva aos cofres das três províncias produtoras. Destarte, qualquer sinal de diminuição na arrecadação fazia aumentar o controle por parte dos fiscos provinciais. Devido aos problemas de extravios e permanente a expansão da fronteira agrícola do café, a administração provincial mineira preocupou-se em criar recebedorias e em meados do século XIX a fronteira de Minas Gerais com o Rio de Janeiro apresentava enorme concentração de postos fiscais.

Qualquer acordo entre Minas e São Paulo acabou sendo substituído por novas medidas de controle por parte do governo paulista. ${ }^{55} \mathrm{Em} \mathrm{1844,}$ exigiam-se "assinaturas dos Administradores das Recebedorias para conferir Guias apresentadas nos Registros da Provincia de São Paulo."56 Em 1846, as guias mineiras deviam ser apresentadas nas coletorias paulistas dos municípios nas rotas de Minas Gerais para os portos. ${ }^{57}$ Em 1847, a Mesa de Rendas do porto de Ubatuba (SP) recolheu guias de exportações mineiras suspeitas de acompanharem tabaco de origem paulista e o presidente de São Paulo pediu averiguação da contrapartida nos livros das recebedorias de Minas Gerais. ${ }^{58}$

A pequena taxa de exportação do café em Minas Gerais gerou especial indisposição. A arroba de café em Minas pagava 3\% sobre $2 \$ 000$ réis (taxa de $\$ 60$ réis), que no Rio de Janeiro era taxada em 4\% sobre o preço médio das pautas semanais da Alfândega, o qual atingiu niveis superiores a $3 \$ 000$ em meados da década de 1840 e $5 \$ 000$ na virada para 1850 (taxa de $\$ 200$ réis). Segundo a presidência do Rio de Janeiro, a disparidade estimulava a fraude e em 1845/46 seu café era exportado como mineiro:

Diz-se que alguns fazendeiros moradores entre o [rio] Paraiba e o [rio] Paraibuna [no Rio de Janeiro] onde se acha o registro de Minas [ponte sobre o Paraibuna], pagavam nele o imposto do café, e o exportavam guiado como de produção mineira. [...] A fraude faz-se ainda de outra maneira: alguns tropeiros de Minas, chegando aos registros daquela provincia anunciam querer pagar o imposto de 300 arrobas de café, quando na realidade não conduzem senão 50, sendo resto da carga milho e feijão, ou mesmo toucinho. 0 administrador do registro, ou porque Ihe pareça que o número de animais tocados não pode trazer mais do que as 300 arrobas, ou porque pela muita afluência de tropas, que de propósito se reuniam na ocasião da passagem, não possa verificar toda a carga, ou porque, posto conheça o engano, tem interesse em cobrar antes o imposto sobre 300 arrobas do que sobre 50, o faz em boa ou má fé. [...] 0 individuo que teria de pagar $3 \$ 000$ pelas 50 arrobas de café, não duvida pagar $18 \$ 000$; porque vendendo a guia por $24 \$ 000$ ganha $6 \$ 000$; e o comprador dessa guia não duvida comprá-la por $24 \$ 000$ porque tendo de pagar no Consulado $30 \$ 000$ pelas 250 arrobas, lucra também $6 \$ 000.59$ 


\section{0}

0 Convênio do Café de 1851 gerou conflitos entre as províncias do Rio de Janeiro e São Paulo. Os exportadores paulistas foram tentados a escapar do pagamento nos seus registros, pois era mais dificil deixar de efetuar o pagamento no Rio (TESSITORE, Viviane. As Fontes da Riqueza Pública. 1995. Dissertação de Mestrado. Faculdade de Filosofia, Letras e Ciências Humanas, Universidade de São Paulo, São Paulo, 1995., p.152).

\section{1}

Reclamação da Presidência de Minas à do Rio, 15 de novembro de 1859, apud RIBEIRO, Joaquim Cypriano. Roteiro dos Exactores da Fazenda Provincial de Minas Gerais. [Ouro Preto]: Typ. do Diario de Minas, 1876. p.257-258.

\section{2}

Arquivo Público Mineiro, Biblioteca, Tabelas da Mesa das Rendas Provinciais, Vol.3; Arquivo Público Mineiro, Balanços e Orçamentos Apresentados à Assembléia Legislativa Provincial no ano de 1859, tabela 4; Idem, 1861, tabela 4. Cf. RESTITUTTI, Cristiano Corte. As fronteiras da província: rotas de comércio interprovincial, Minas Gerais, 1839-1884. Dissertação (Mestrado em Economia). Faculdade de Ciências e Letras de Araraquara, UNESP, 2006. Disponivel em: <http://www.athena. biblioteca.unesp.br>. Acesso em: 31 jul. 2009.

63 GERBER, Henrique. Noções Geográficas e Administrativas da Provincia de Minas Gerais. Rio de Janeiro: Tipografia de Georges Leuzinger, 1863 p.44. Sobre os extravios às taxa nas rotas de comércio interprovincial, ver RESTITUTTI, Cristiano Corte. Op.Cit., esp. seção 2.3 ("As formas de subregistro", p.48-58), e segunda parte (passim). Disponivel em: <http://www.athena.biblioteca. unesp.br>. Acesso em: 31 jul. 2009.

\section{4}

Regulamento de 24 de setembro de 1860, artigos 71 e 87, apud MAGALHÃES, Hildebrando. 0 Café em Minas Geraes. Piracicaba: Typ. da Livraria Giraldes, 1933. p.19-21. Cf. Ibidem, p. 20-26.

\section{5}

Parecer do conselheiro Joaquim Delfino Ribeiro da Luz fornecido pelo ministro da Marinha ao visconde de Rio Branco, Ministro da Fazenda, apud MAGALHÃES, Hildebrando. Op.Cit., p.27-28.
A acusação era conjetural, pois este tipo de fraude nunca foi documentado. Não concorrendo Minas Gerais com medidas que inviabilizassem esta fraude, o Rio de Janeiro ameaçava bitributar o café mineiro, em prejuizo dos produtores e exportadores, os quais se esforçariam, então, para evadir do fisco mineiro. Após uma década de acusações mútuas, as presidências das províncias de Minas e Rio assinaram o Convênio de 17 de junho de 1851. Os direitos de exportação do café mineiro e fluminense seriam cobrados indistintamente na alfândega do Rio de Janeiro e foram fixadas como exportações mineiras 9,03\% do total do café taxado. 60

Em fins da década de 1850, os mineiros sabiam que a participação de seu café superara 9,03\% do total de Minas e Rio. A Mesa das Rendas continuou anotando as saídas de café pelas recebedorias e calculou a quantidade de café mineiro não contabilizado pelo Convênio em 250 mil arrobas no exercício 1858/59. ${ }^{61}$ No quinquênio fiscal 1854-59, aqueles 9,03\% do Convênio representaram 839 mil arrobas anuais e as recebedorias mineiras registraram apenas 767 mil arrobas anuais. ${ }^{62}$ Porém, contabilizando-se os extravios estimados pelo engenheiro Gerber, as exportações mineiras totalizaram um milhão e vinte mil arrobas anuais. 0 sub-registro foi especialmente notável nas novas zonas cafeicultoras, pois enquanto as recebedorias anotaram apenas três mil arrobas de café exportadas anualmente em direção a São Fidélis e Campos, Gerber calculou o mesmo comércio em 150 mil arrobas anuais. 630 Convênio não foi renovado para 1860/61 e neste ano fiscal Minas Gerais exportou por suas recebedorias 1,7 milhão de arrobas de café.

0 governo do Rio de Janeiro temia a volta dos antigos problemas e, "para defender os seus interesses" e com o consentimento da província de Minas, mandou prover as recebedorias de Minas com agentes fiscais fluminenses. As guias de café mineiro só seriam aceitas na Alfândega do Rio se apresentassem o visto destes fiscais. Apesar deste controle, as velhas acusações de ambas as partes se reproduziram nas décadas de 1860 e 1870: o fisco fluminense desconfiava de fraude e não aceitava guias suspeitas, os exportadores mineiros temiam bitributação e extraviavam das recebedorias. 64 A questão não seria solucionada caso o café mineiro continuasse a pagar taxa inferior ao café fluminense:

\footnotetext{
A pauta de Minas dura um ano e ás vezes mais, porque não a renovam [os legisladores mineiros], como devem; sendo ali o preço fixo para cada arroba de café de $4 \$ 200$ ou $\$ 300$ por quilograma, ao passo que aqui [Rio de Janeiro] é sempre variável e de maior soma ou do dobro; segue-se que o café mineiro, não obstante sofrer o mesmo imposto que o da província do Rio de Janeiro, é muito menos onerado do que este, visto como $4 \%$ sobre o preço de $4 \$ 200$ produzem muito menor quantidade do que a que percebe a província do Rio de Janeiro sobre o seu café, avaliado sempre por preço muito mais elevado. Assim, torna-se manifesto o interesse que há da parte dos produtores de café e dos que negociam nesse gênero, em fazê-lo passar antes por café mineiro do que fluminense. Daqui proveio a fraude de que se queixava outrora a administração fiscal da província do Rio de Janeiro, de que os administradores das recebedorias de Minas cometiam o abuso de cobrar direitos do café fluminense e de expedir guias, como fora de Minas, prestando-se, assim, aos pedidos dos produtores de café fluminense, residentes nas proximidades das estações mineiras. 65
}

Conseqüentemente, os casos documentados de bitributação se tornaram mais freqüentes. Para garantir que todas as guias mineiras fossem consideradas legítimas, os dados completos das guias de café expedidas 


\section{6}

"As recebedorias mineiras enviarão, até o dia 5 de cada mês, à Mesa de Rendas estabelecida no Consulado da Corte, uma demonstração do café exportado no mês anterior, com declaração das guias expedidas, número de cada uma, sua data, procedência e quantidade dos gêneros e nome do dono ou da pessoa por cuja conta se faz a exportação" (Ordem da Presidência de 18 de abril de 1875, apud RIBEIRO, Joaquim Cypriano. Roteiro dos Exactores da Fazenda Provincial de Minas Gerais. [Ouro Preto]: Typ. do Diario de Minas, 1876. p.276-277).

\section{7}

Apud MAGALHÃES, Hildebrando. O Café em Minas Geraes. Piracicaba: Typ. da Livraria Giraldes, 1933. p.30.

68

TAVARES BASTOS, A. C. A Provincia: estudo sobre a descentralização no Brasil. 3a edição feita sobre a $1^{1 a}$ edição de 1870. São Paulo: Companhia Editora Nacional, 1975. p.211.

69

FERREIRA, Gabriela Nunes. Centralização e descentralização: o debate entre Tavares Bastos e visconde de Uruguai. São Paulo: Ed. 34, 1999. p.103.

70

Ibidem. p.98. nas recebedorias eram mensalmente remetidos à capital do Império para confronto com as guias recolhidas. 66

0 problema foi finalmente resolvido pela lei mineira $n^{\circ} 2892$ de 5 de novembro de 1882 que orçou a receita do ano financeiro de 1883/84:

Art. $4^{\circ}$ - A pauta para cobrança desta contribuição [taxa de exportação do café] será organizada nos meses de março, junho, setembro e dezembro de cada ano, pelo presidente da província, que a fixará de acordo com o preço médio do mesmo gênero e de conformidade com a pauta da alfândega da corte. ${ }^{67}$

Esta lei mineira foi publicada após quarenta anos de insistência do governo fluminense para que a taxa de exportação do café mineiro fosse aproximada à taxa fluminense.

\section{Considerações finais}

A criação das taxas de exportação e itinerárias em Minas Gerais foi tardia, comparando tão-somente com a evolução fiscal no Rio de Janeiro e em São Paulo. Estes títulos não integravam a receita mineira quando foi instalada a primeira Assembléia Provincial, em 1835. Todavia, apenas em Minas as taxas itinerárias constituiram imposto equivalente aos direitos de entrada.

0 estabelecimento das taxas de exportação e itinerárias a partir de c.1840 gerou conflitos fiscais. As taxas de exportação protagonizaram guerras fiscais desde os tempos do dízimo. Os exportadores mineiros conviveram com o risco de bitributação desde a década de 1820, quando as taxas de exportação foram criadas nas províncias de São Paulo e do Rio de Janeiro. Depois da extinção dos dízimos em Minas, aquelas províncias passaram a temer que suas mercadorias fossem exportadas como mineiras. Por ser província interna, com custos de transporte mais elevados do que as demais, a taxa de exportação em Minas seria necessariamente mais branda.

As taxas itinerárias, ao reeditarem os antigos direitos de entrada e serem comparados aos impostos de importação, tributavam objeto privativo da esfera geral do Império. Além disso, oneravam as importações de duas províncias cujos custos de transporte desde o Rio de Janeiro eram quase proibitivos. Nas palavras de Tavares Bastos, a introdução deste item de receita no orçamento de Minas Gerais suscitou "memorável controvérsia sobre taxas itinerárias, erroneamente comparadas a direitos de importação."68 No debate entre Tavares Bastos e o Visconde do Uruguai, o primeiro

reconhece como renda peculiar do governo nacional os impostos de importação, entendidos em seu sentido literal: taxas de entrada de produtos estrangeiros nas alfândegas. Citando Visconde de Uruguai, Tavares Bastos afirma que muitos exemplos transcritos por ele - sobre as incursões das provincias no campo dos impostos de importação - padecem de dois defeitos: o exagero dos inconvenientes das leis provinciais; e a confusão quanto à natureza dos impostos criados pelas Assembléias Provinciais. Tender-se-ia, segundo o autor, a incluir sob a rubrica 'impostos de importação' outras taxas de natureza diferente: as taxas sobre o consumo local de certos gêneros; e as taxas itinerárias. ${ }^{69}$

Por outro lado, o Visconde do Uruguai assinalara que:

As Assembléias Provinciais têm atacado os impostos gerais, principalmente de importação e exportação [...] Depois que em 1845 cessou o suprimento às provincias, voltaram-se ainda mais as Assembléias Provinciais para novas excursões no campo dos impostos gerais. 70 
71

DINIZ, Adalton Franciozo. Centralização política e apropriação de Riqueza: análise das finanças do Império Brasileiro (1821 - 1889). 2002. Tese de doutorado. Faculdade de Filosofia, Letras e Ciências Humanas, Universidade de São Paulo, São Paulo, 2002. p.80.

72

Minas Gerais. Relatorio apresentado ao ill.mo e ex.mo snr. coronel Joaquim Camillo Teixeira da Motta, vice-presidente da provincia de Minas Geraes, pelo Inspector da Meza das Rendas, Affonso Celso Assiz Figueiredo, em 16 de julho de 1862. Ouro Preto: Typ. de Silva, 1862, mapas 1 e 8A; Minas Gerais. Relatorio Apresentado á Assembléa Legislativa Provincial de MinasGeraes na sessão ordinaria de 1869 pelo presidente da mesma provincia, dr. José Maria Corrêa de Sá e Benavides. Rio de Janeiro: Typ. Universal de Laemmert, 1870, anexo 9 - Mapa n.4.

73

Lei $n .39$ de 21 de julho de 1892.
Acreditamos que o estímulo à interferência da província de Minas Gerais nos impostos de importação foi a extinção das taxas alfandegárias favoráveis aos ingleses, vigentes desde 1810, através da Lei Alves Branco de 1844. Segundo Adalton Diniz, após o fim do Tratado de Comércio com a Inglaterra "o Império pôde tributar livremente as importações. Essa liberdade possibilitou que o Estado extraisse o máximo de receita dessa importante fonte de recursos."71

Os dois impostos do sistema fiscal de Minas Gerais provincial estudados neste artigo têm sua origem em direitos dos tempos da capitania. Os direitos de entrada e os dizimos eram as principais fontes de renda da Junta da Fazenda da capitania de Minas Gerais, ao lado dos quintos do ouro. A versão provincial destes direitos também foi importante item de receita. A partir de 1839, ambos os impostos passaram a ser cobrados nas recebedorias, postos fiscais idênticos aos registros extintos em 1832/33.

As taxas de exportação e as taxas itinerárias, incluindo suas modalidades de direitos de entrada - a taxa de bestas novas e a taxa de exceção sobre as importações estrangeiras - responderam por 58\% da arrecadação consolidada no decênio fiscal $1850-60$ e por $66 \%$ no ano financeiro de $1867 / 68 .^{72} \mathrm{~A}$ importância destes direitos provinciais não cessou de aumentar, mormente devido ao café. Assim, continuaram existindo na República. Os impostos de exportação e importação representaram $85 \%$ da receita estadual orçada para o ano de $1893^{73}$. 